\title{
EVALUASI KESESUAIAN PERAIRAN UNTUK BUDIDAYA IKAN DALAM KERAMBA JARING APUNG DI KABUPATEN MALUKU TENGGARA BARAT PROVINSI MALUKU
}

\author{
Akhmad Mustafa**\#, Tarunamulia"), Hasnawi*), dan I Nyoman Radiarta** \\ *) Balai Riset Perikanan Budidaya Air Payau dan Penyuluhan Perikanan \\ Jl. Makmur Dg. Sitakka 129 Maros 90512, Sulawesi Selatan \\ *) Balai Riset dan Observasi Laut, Perancak \\ Jl. Baru Prancak, Budeng, Jembrana, Budeng, Kec. Jembrana, Kabupaten Jembrana, Bali 82218 \\ (Naskah diterima: 10 April 2018; Revisi final: 14 Agustus 2018; Disetujui publikasi: 14 Agustus 2018)
}

\begin{abstract}
ABSTRAK
Kabupaten Maluku Tenggara Barat (MTB) memiliki potensi untuk pengembangan budidaya ikan dalam keramba jaring apung (KJA), tetapi belum tersedia data karakteristik perairannya. Penelitian bertujuan untuk mengkaji kesesuaian dan daya dukung perairan berdasarkan karakteristik perairannya untuk budidaya ikan dalam KJA di kawasan pesisir Kabupaten MTB Provinsi Maluku, Indonesia. Data karakteristik perairan yang dikumpulkan berupa pasang surut, kecepatan dan arah arus, kedalaman, kecerahan, suhu, salinitas, oksigen terlarut, $\mathrm{pH}$, nitrat, nitrit, nitrogen amonia total, fosfat, padatan tersuspensi total, dan bahan organik total air, serta jenis substrat dasar. Kesesuaian perairan ditentukan melalui analisis dengan weighted linear combination dalam sistem informasi geografis (SIG) dan luasan daya dukung perairan untuk budidaya ikan dalam KJA didasarkan pada referensi yang telah ada. Hasil penelitian menunjukkan bahwa secara umum karakteristik perairan Kecamatan Tanimbar Utara, Wuarlabobar, dan Selaru, Kabupaten MTB dapat mendukung kegiatan budidaya ikan dalam KJA, namun kedalaman perairan yang relatif dangkal yang menjadi faktor pembatas dalam kesesuaian perairan untuk kegiatan budidaya ikan dalam KJA. Dari 67.287,84 ha kawasan pesisir yang diteliti di Kabupaten MTB dijumpai yang tergolong sangat sesuai seluas 1.564,43 ha; cukup sesuai seluas 10.687,78 ha; kurang sesuai sesuai 2.103,92 ha; dan tidak sesuai seluas 52.931,71 ha untuk budidaya ikan dalam KJA. Di kawasan pesisir Kecamatan Tanimbar Utara, Wuarlabobar, dan Selaru dapat dilakukan budidaya ikan dalam KJA dengan daya dukung perairan masing-masing seluas 363, 292, dan 570 ha yang dapat digunakan untuk masing-masing 5.445; 4.380; dan 8.550 unit KJA ukuran $8 \mathrm{~m} \mathrm{x}$ $8 \mathrm{~m}$.
\end{abstract}

\section{KATA KUNCl: kesesuaian perairan; budidaya ikan; keramba jaring apung; Maluku Tenggara Barat}

ABSTRACT: Waters suitability evaluation for floating net cagemariculture in Maluku Tenggara Barat District, Maluku Province. By: Akhmad Mustafa, Tarunamulia, Hasnawi, and I Nyoman Radiarta

Maluku Tenggara Barat District has potential waters for the development of floating net cage mariculture. However, the characteristics and quality of the waters have not been well studied. This study was aimed to assess the suitability and carrying capacity of coastal waters of M aluku Tenggara Barat based on the requirements of net cage mariculture. The measured waters characteristics included tidal, current velocity (speed and direction), water depth, transparency, temperature, salinity, dissolved oxygen, $\mathrm{pH}$, nitrate, nitrite, total ammonia nitrogen, phosphate, total suspended solids, and total organic matter as well as bottom substrate types. The weighted linear combination (WLC) method in geographic information system (GIS) was used to determine the level of waters suitability and carrying capacity to support floating net cage mariculture operation. TheW LC criteria used werebased on the existing standard environmental criteria. The results showed that the coastal waters of Tanimbar Utara, Wuarlabobar, and Selaru sub-districts were suitable for fish culture in floating net cage. Nevertheless, the relatively shallow water depth in the study area was identified as the primary limiting factor of suitability. Of the total of the coastal areas studied $(67,287.84 \mathrm{ha})$, 1,564.43 ha; $10,687.78$ ha; $2,103.92$ ha; and $52,931.71$ ha were respectively categorized as very suitable,

\footnotetext{
\# Korespondensi: Balai Riset Perikanan Budidaya Air Payau dan Penyuluhan Perikanan. Jl. Makmur Dg. Sitakka 129 Maros 90512, Sulawesi Selatan, Indonesia.

Tel. + 62411371544

E-mail: akhmadmustafa@yahoo.com
} 
moderately suitable, marginally suitable, and not suitable for fish culture in floating net cage. The carrying capacity of the coastal waters of Tanimbar Utara, Wuarlabobar and Selaru sub-districts were estimated able to support 5,445; 4,380; and 8,550 floating net cage units sized $8 \mathrm{~m} \times 8 \mathrm{~m}$ distributed in total farm areas of 363, 292, and 570 ha, respectively.

\section{KEYWORDS: $\quad$ waters suitability; fish culture; floating net cage; Maluku Tenggara Barat}

\section{PENDAHULUAN}

Salah satu keluaran yang diharapkan dari Keputusan Menteri Kelautan dan Perikanan No. 12/KEPMEN-KP/ 2015 tentang Tim Percepatan Investasi di Bidang Kelautan dan Perikanan untuk lima pulau terdepan: Simeulue (Nanggroe Aceh Darussalam), Natuna (Kepulauan Riau), Sangihe (Sulawesi Utara), Saumlaki (Maluku), dan Merauke (Papua) adalah tersedianya profil sumber daya perikanan tangkap dan perikanan budidaya di kelima pulau terdepan tersebut. Perikanan budidaya (akuakultur) yang diterapkan di Indonesia meliputi budidaya laut (marikultur), budidaya air payau (tambak), budidaya air tawar (kolam), perairan umum, dan minapadi. Di antara kelima jenis budidaya tersebut, potensi lahan untuk marikultur adalah terbesar yaitu seluas 12.545 .072 ha atau $70,70 \%$ dari luas total potensi akuakultur di Indonesia. Namun, tingkat pemanfaatannya masih tergolong kecil yaitu 2,60\% (KKP, 2015). Oleh karena itu, peluang pengembangan marikultur di Indonesia masih sangat besar.

Salah satu faktor penentu keberhasilan kegiatan marikultur adalah pemilihan lokasi yang tepat (Mustafa et al., 2011, 2017; Purnawan et al., 2015). Kesalahan dalam pemilihan lokasi dapat menyebabkan kegiatan marikultur tidak berlangsung lama (Philipose et al., 2013). Perkembangan kegiatan marikultur di Indonesia masih banyak yang mengalami kesalahan dalam perencanaan, penyebabnya adalah kurangnya pengetahuan tentang lingkungan perairan yang tidak cocok bagi kegiatan marikultur, serta data berbagai faktor yang tidak sesuai pada lokasi kegiatan marikultur. Salah satu kegiatan marikultur yang dilakukan di Indonesia, termasuk di Kabupaten Maluku Tenggara Barat (MTB) adalah budidaya ikan dalam keramba jaring apung (KJA) di laut. Kementerian Kelautan dan Perikanan melalui Direktorat Jenderal Perikanan Budidaya mulai tahun 2017 fokus dalam upaya optimalisasi produksi melalui program revitalisasi KJA. Keramba jaring apung yang dikelola masyarakat sejauh ini sebanyak 15.583 lubang yang merupakan bantuan KJA dari lintas kementerian (KKP News, 2017). Berbagai komoditas yang dapat dibudidayakan dalam KJA adalah ikan bandeng (Chanos chanos), ikan kakap (Lutjanus sp.), ikan kerapu (Epinephelus sp.), ikan beronang (Siganus sp.), ikan kuwe (Caranx sp.), lobster (Panulirus sp.), dan udang vaname (Litopenaeus vannamei) (Radiarta et al., 2014;
KKP, 2015; Effendi et al., 2016). Komoditas tersebut merupakan komoditas yang berbasis perairan yaitu aktivitas hidup, tumbuh, dan berkembang biak dalam perairan, sehingga menuntut kondisi tertentu untuk aktivitas tersebut.

Evaluasi kesesuaian lahan/perairan merupakan suatu proses pendugaan keragaan lahan/perairan apabila digunakan untuk tujuan tertentu (FAO, 1985) atau sebagai metode yang menjelaskan atau memprediksi kegunaan potensial dari lahan/perairan (van Diepen et al., 1991; Radiarta et al., 2013) dan bertujuan untuk menyelamatkan sumber daya yang ada secara berkelanjutan (Richard \& Ogba, 2016). Dengan demikian, evaluasi kesesuaian Iahan/perairan merupakan tahapan perencanaan penggunaan lahan/ perairan yang strategis. Kesesuaian lahan/perairan merupakan suatu tahapan awal dalam kegiatan akuakultur yang memengaruhi kesuksesan dan keberlanjutannya, serta dapat memecahkan konflik antara berbagai kegiatan dan membuat penggunaan lahan/perairan lebih rasional (Rodriguez-Gallego et al., 2012; Hasnawi et al., 2013; Tarunamulia et al., 2015; Bano et al., 2016). Faktor lainnya yang perlu diperhatikan selain kesesuaian lahan/perairan yang menentukan kesuksesan dan keberlanjutan dari kegiatan budidaya ikan dalam KJA adalah daya dukung perairan. Pemanfaatan perairan yang tidak terkendali terhadap budidaya ikan dalam KJA di suatu kawasan pesisir yang tanpa adanya pengaturan, dikhawatirkan akan terlampauinya daya dukung perairan yang berdampak pada penurunan kuantitas, kualitas, dan kontinuitas produksi ikan dalam KJA (Grigorakis \& Rigos, 2011; Gorlach-Lira et al., 2013; Price et al., 2015). Daya dukung perairan merupakan konsep dasar yang dikembangkan untuk pengelolaan sumber daya alam dan lingkungan secara berkelanjutan (Stigebrandt, 2011; Ayllón et al., 2012; Ross et al., 2013). Penelitian dilakukan dengan tujuan untuk mengevaluasi kesesuaian dan daya dukung perairan Kabupaten MTB untuk budidaya ikan dalam KJA di laut berdasarkan karakteristik perairannya.

\section{BAHAN DAN METODE}

\section{Lokasi dan Waktu Penelitian}

Penelitian dilaksanakan di kawasan pesisir Kabupaten MTB tepatnya di dua pulau terdepan yaitu 
Pulau Larat (Kecamatan Tanimbar Utara) dan Pulau Selaru (Kecamatan Selaru) dan satu kecamatan di Pulau Utama (Pulau Yamdena) yaitu Kecamatan Wuarlabo bar. Analisis kualitas air dilakukan di Laboratorium Air Balai Penelitian dan Pengembangan Budidaya Air Payau (BPPBAP) yang berubah nomenklatur menjadi Balai Riset Perikanan Budidaya Air Payau dan Penyuluhan Perikanan (BRPBAP3) di Maros, Sulawesi Selatan. Penelitian dilaksanakan pada bulan Oktober dan November 2015.

\section{Pengumpulan Data}

Data yang dikumpulkan meliputi data primer dan sekunder. Data primer mencakup pasang surut (pasut), kedalaman, kecepatan dan arah arus, salinitas, suhu, $\mathrm{pH}$, oksigen terlarut, kecerahan, nitrat $\left(\mathrm{NO}_{3}\right)$, nitrit $\left(\mathrm{NO}_{2}\right)$, nitrogen amonia total, fosfat $\left(\mathrm{PO}_{4}\right)$, padatan tersuspensi total, dan bahan organik total air, serta substrat dasar.

Pasut diketahui dengan memasang water level dan papan berskala pada tempat yang memungkinkan yaitu di Pelabuhan Larat di Pulau Larat, Kecamatan Tanimbar Utara. Pasang surut diamati selama 15 hari (15 piantan) dengan interval pengamatan setiap jam. Pengukuran batimetri atau kedalamam dilakukan secara simultan dengan pengukuran posisi horisontalnya, di mana kedalaman sendiri dilakukan dengan alat ukur kedalaman yang menggunakan gelombang akustik, sedangkan alat ukur horisontalnya menggunakan prinsip penentuan posisi dengan Global Positioning System (GPS). Alat pengukur kedalaman adalah echosounder atau perum gema. Kecepatan dan arah arus diukur masing-masing dengan current meter dan kompas. Substrat dasar diambil dengan menggunakan eickman grab. Jenis substrat dasar ditentukan melalui pengamatan langsung di lapangan.

Kualitas air diukur secara langsung di lapangan dengan menggunakan YSI Pro Plus meliputi: salinitas, suhu, pH, dan oksigen terlarut. Kualitas air lainnya yang diukur langsung di lapangan adalah kecerahan dengan menggunakan piring secchi. Untuk parameter kualitas air lainnya, maka dilakukan pengambilan contoh air dengan menggunakan kemerer water sampler. Contoh air dipreservasi mengikuti petunjuk APHA (2012). Kualitas air yang diukur di labo ratorium adalah nitrat dengan metode reduksi natrium, nitrit dengan metode kalorimetri, nitrogen amonia total dengan metode fenat, fosfat dengan metode asam askorbat, padatan tersuspensi total dengan metode gravimetri, bahan organik total dengan metode tetrimetri mengikuti petunjuk Sutrisyani \& Rohani (2009) dan APHA (2012). Data primer lain berupa citra SPOT-5, SPOT-6, dan SPOT-7 diperoleh dari Lembaga Antariksa dan Penerbangan Nasional (LAPAN).
Data sekunder diperoleh dari berbagai instansi. Peta Rupabumi Indonesia diperoleh dari Badan Informasi Geospasial (BIG), Peta Pola Ruang Wilayah diperoleh dari Badan Perencana Pembangunan Daerah Kabupaten MTB, Maluku Tenggara Barat dalam Angka diperoleh dari Badan Pusat Statistik Kabupaten MTB, dan Laporan Dinas Kelautan dan Perikanan Kabupaten MTB diperoleh dari Dinas Kelautan dan Perikanan Kabupaten MTB.

\section{Analisis Spasial Perairan}

Statistik deskriptif yang meliputi nilai minimal, maksimal, dan rata-rata digunakan untuk mengetahui kondisi umum data perairan yang ada. Peta dibuat dengan memanfaatkan citra yang tersedia yang diintegrasikan dengan data primer dan data sekunder. Untuk masing-masing data tersebut dilakukan interpolasi dengan menggunakan metode kriging, sehingga diperoleh peta-peta tematik (Morain, 1999) untuk setiap paramater perairan.

Faktor kriteria dan penghambat adalah faktor yang dipertimbangkan dalam evaluasi kesesuaian perairan. Faktor kriteria berupa: pasut, kedalaman, kecepatan arus, kecerahan, salinitas, suhu, oksigen terlarut, pH, nitrat, fosfat, dan padatan tersuspensi total perairan, serta jenis substrat dasar seperti telah dilaporkan oleh Ahmad et al. (1991), Mayunar et al. (1995), KLH (2004), dan Mustafa et al. (2011). Faktor penghambat berupa: jarak ke pemukiman, jarak ke sungai, dan jarak ke pelabuhan. Faktor kriteria keterlindungan dari gelombang tidak dipertimbangkan sebagai kriteria dalam evaluasi kesesuaian perairan di kawasan pesisir Kabupaten MTB, sebab lokasi yang dipilih sudah mempertimbangkan informasi yang ada sebelumnya (DKP Kabupaten MTB, 2014). Dikatakan bahwa gelombang yang signifikan di kawasan pesisir Kabupaten MTB hanya terjadi di tempat tertentu di perairan Laut Banda yang menyebabkan kemunduran garis pantai dan munculnya komunitas organisme akuatik lain.

Penilaian terhadap tingkat kesesuaian perairan untuk ikan dalam KJA dilakukan dengan metode tumpang-susun peta-peta tematik yang telah dibuat dengan metode pembobotan pada software ArcGIS versi 9.3 dengan faktor pembobot yang telah disusun. Bobot dari masing-masing parameter lingkungan ditentukan dengan pair-wise comparison, yang merupakan bagian dari proses pengambilan keputusan yang dikenal dengan metode analytical hierarchy process (AHP) (Saaty, 1977). Setelah seluruh skor dan bobot ditentukan, langkah selanjutnya adalah melakukan analisis spasial kesesuaian perairan. Analisis ini dilakukan dengan metode weighted linear combination (Malczewski, 1999), yang merupakan 
aplikasi dari multi-criteria evaluation. Analisis dengan weighted linear combination dilakukan dengan pemodelan yang terdapat dalam perangkat lunak ArcGIS versi 9.3.

Luasan yang dapat digunakan untuk budidaya ikan dalam KJA didasarkan pada referensi yang telah ada (Radiarta et al., 2004). Luasan yang disarankan tersebut yang juga dapat menggambarkan daya dukung perairan yang dipertimbangkan berdasarkan luas yang sesuai untuk budidaya ikan dalam KJA.

\section{HASIL DAN BAHASAN}

\section{Karakteristik Perairan}

Budidaya ikan dalam KJA adalah teknologi yang paling banyak digunakan untuk kegiatan marikultur dan memanfaatkan sumber daya yang mudah didapat, yaitu air laut (Silva-Cruz et al., 2011). Dengan demikian, karakteritsik air laut di kawasan pesisir yang berpengaruh terhadap keberhasilan dan keberlanjutan kegiatan budidaya ikan dalam KJA menjadi sangat penting untuk dicermati.

Pasut merupakan salah satu gejala laut yang besar pengaruhnya terhadap biota laut khususnya organisme akuatik yang dibudidayakan di kawasan pesisir. Hasil analisis pasut di kawasan pesisir Kabupaten MTB mendapatkan perbedaan pasang dan surut yang dapat mencapai 2,4 $\mathrm{m}$. Dari perbandingan konstanta harmonis pasut yang berasal dari data BIG untuk data dari Larat (Kecamatan Tanimbar Utara, Kabupaten MTB) dan data prediksi Dinas Hidro-Oseanografi (DISHIDROS) TNI Angkatan Laut untuk data dari Kota Tual (Provinsi Maluku) didapatkan bilangan Formzhal yang berbeda pada data prediksi yang berbeda, tetapi masih termasuk pada tipe pasut yang sama yaitu campuran: condong ke semidiurnal.

Arus laut merupakan pencerminan langsung dari pola angin dan gerakan bumi yang memberi kemungkinan adanya aerasi pada lokasi budidaya ikan dalam KJA. Kecepatan arus di Kabupaten MTB berkisar antara 19,46 dan 38,46 cm/dt (Tabel 1). Kecepatan arus yang tinggi dijumpai di Kecamatan Tanimbar Utara dan arah arusnya bergerak dari barat laut ke tenggara. Di kawasan pesisir Kecamatan Wuarlabobar, arah arus bergerak dari barat daya ke timur laut. Arah arus dari utara ke selatan, dari barat ke timur, dan dari selatan ke utara dijumpai di kawasan pesisir Kecamatan Selaru. Lokasi budidaya laut yang berada pada arus perairan yang cepat dapat merusak konstruksi wadah budidaya ikan dalam KJA, sedangkan arus yang lambat dapat menyebabkan kurangnya nutrien untuk pertumbuhan komoditas yang dibudidayakan dan lebih lanjut hama pengganggu lebih mudah menempel pada wadah budidaya. Penempelan hama pengganggu pada wadah budidaya ikan dalam KJA dapat menyebabkan jaring tertutup sehingga sirkulasi air menjadi tidak lancar yang berdampak kurang baik terhadap ikan yang dibudidayakan. Arus berfungsi untuk membawa massa air baru yang mengandung oksigen terlarut yang cukup untuk aktivitas respirasi ikan. Arus juga membawa sisa-sisa pakan, feses, dan buangan metabolik ikan keluar jauh dari KJA, serta membawa pakan alami ke dalam KJA (Beveridge, 1996). Arus yang terlalu cepat tidak dikehendaki karena akan memberikan gaya dinamis yang besar pada sistem KJA, sehingga berpengaruh pada sistem keamanan. Ramelan (1998) menyatakan bahwa arus untuk budidaya ikan dalam KJA harus berada pada kisaran 20-40 cm/dt.

Lokasi untuk kegiatan budidaya ikan dalam KJA sebaiknya pada waktu surut masih digenangi air sedalam minimal 0,5 m. Kisaran kedalaman air yang diukur di Kecamatan Tanimbar Utara, Wuarlabobar, dan Selaru berturut-turut 2,0-22,0 m; 2,0-30,0 m; dan 2,115,1 m. Namun demikian, data yang ada menunjukkan bahwa perairan lepas Kabupaten MTB memiliki kedalaman perairan yang sangat dalam. Di Kecamatan Tanimbar Utara, di bagian selatan digolongkan dangkal, sedangkan di bagian utara mencapai kedalaman 561$1.021 \mathrm{~m}$ dan di bagian timur mencapai kedalaman 1.123-3.500 m (DKP Kabupaten MTB, 2014). Dilaporkan pula bahwa kedalaman di bagian utara dan timur Kecamatan Wuarlabo bar tergolong dangkal, sedangkan bagian timur lainnya dapat mencapai $685-1.150 \mathrm{~m}$, di bagian utara mencapai $945-5.575 \mathrm{~m}$, dan juga di bagian barat lainnya mencapai 570-1.475 m.

Untuk budidaya ikan dalam KJA, kedalaman perairan yang minimal ditentukan oleh dimensi kantong jaring, beda pasut, dan jarak minimal antara dasar kantong dan dasar perairan. Jika kantong jaring memiliki tinggi 3,0 m; beda pasang surut sebesar 2,4 m seperti telah disebutkan sebelumnya di Kabupaten MTB kemudian jarak antara dasar perairan dan dasar kantong sebesar 2,0 m; maka kedalaman minimal budidaya ikan dalam KJA harus sedikitnya 7,4 m. Pertimbangan untuk kedalaman perairan maksimal juga ditentukan oleh mahalnya material konstruksi, khususnya mooring system, besarnya biaya operasional, serta sulitnya proses instalasi budidaya ikan dalam KJA (Beveridge, 1996). Oleh karena itu, kedalaman perairan untuk budidaya ikan dalam KJA lebih baik tidak lebih dari 15,0 m. Untuk kegiatan budidaya ikan dalam KJA memerlukan jarak paling sedikit 4,0-5,0 m dari KJA ke dasar perairan dengan substrat dasar dominan pasir atau pecahan karang (Beveridge, 1996).

Jenis substrat dasar perairan dapat menjadi indikator tentang keadaan oseanografi setempat yang dapat digunakan untuk menentukan tingkat kemudahan dalam pembangunan konstruksi KJA yang 
digunakan. Untuk budidaya ikan dalam KJA, substrat dasar yang dikehendaki adalah pasir, pecahan karang, dan karang (Vairappan \& Chung, 2006). Substrat dasar yang dijumpai di lokasi penelitian Kabupaten MTB adalah lumpur, pasir, karang, pasir + lumpur, dan pasir + lumpur + lamun, merupakan substrat dasar yang baik untuk budidaya ikan dalam KJA. Oleh karena itu, lokasi yang baik untuk budidaya ikan dalam KJA berdasarkan substrat dasar berada di ketiga kecamatan yang dikaji yaitu Kecamatan Tanimbar Utara, Wuarlabobar, dan Selaru. Jenis substrat dasar di Kecamatan Selaru didominasi oleh jenis substrat dasar pasir dan karang yaitu masing-masing $42,8 \%$ dan $28,6 \%$ dari jumlah contoh substrat dasar.

Kecerahan atau kekeruhan air merupakan salah satu indikator yang digunakan untuk menentukan lokasi untuk budidaya ikan dalam KJA. Di perairan Kecamatan Wuarlabo bar didapatkan kecerahan perairan antara 2,0 $m$ dan 20,6 m atau 67\%dan 100\%(Tabel 1). Kecerahan perairan antara 2,1 m dan 13,6 m atau 68\%dan 100\% dijumpai di perairan Kecamatan Selaru (Tabel 1). Telah dilaporkan pula bahwa kecerahan perairan di Kecamatan Tanimbar Utara, Wuarlabobar, dan Selaru berturut-turut dikategorikan tinggi (13-15 $\mathrm{m})$, sedangtinggi (8-17 m), dan buruk-sedang (4-11 m) (DKP Kabuapten MTB, 2014).

Secara umum suhu perairan di Indonesia mempunyai perubahan suhu baik harian maupun tahunan, biasanya berkisar antara $27^{\circ} \mathrm{C}-32^{\circ} \mathrm{C}$ dan ini tidak berpengaruh terhadap kegiatan budidaya. Ikan merupakan biota poikiloterm, yang mana suhu tubuhnya naik turun sesuai dengan suhu lingkungan; sebab itu, semua proses fisiologis ikan dipengaruhi oleh suhu lingkungan (Singh et al., 2013). Secara umum, suhu perairan laut di daerah tropis tidak akan berbeda jauh dari satu lokasi ke lokasi perairan yang lain. Hal ini terlihat juga di Kabupaten MTB, di mana suhu perairan relatif sama pada kecamatan yang berbeda. Suhu perairan laut di Kecamatan Tanimbar Utara, Wuarlabobar, dan Selaru masing-masing antara $26,6^{\circ} \mathrm{C}-29,2^{\circ} \mathrm{C} ; 27,0^{\circ} \mathrm{C}-28,0^{\circ} \mathrm{C}$; dan $26,7^{\circ} \mathrm{C}-28,2^{\circ} \mathrm{C}$ (Tabel 1). Telah dilaporkan sebelumnya (DKP Kabupaten MTB, 2014) bahwa suhu perairan di Kecamatan Tanimbar Utara, Wuarlabobar, dan Selaru berturut-turut berkisar antara $25,43^{\circ} \mathrm{C}-25,60^{\circ} \mathrm{C} ; 25,01^{\circ} \mathrm{C}-26,03^{\circ} \mathrm{C}$; dan $26,80^{\circ} \mathrm{C}$ $27,40^{\circ} \mathrm{C}$. Kisaran suhu demikian masuk dalam kategori perairan yang sangat sesuai untuk kegiatan marikultur.

Salinitas menggambarkan padatan total di dalam air setelah semua karbonat dikonversi menjadi oksida, semua bromid, dan iodida telah digantikan oleh klorida, dan semua bahan organik telah dioksidasi. Semua jenis ikan menghendaki salinitas optimal untuk hidup dan pertumbuhannya. Salinitas yang ideal untuk pertumbuhan ikan karang adalah 30-34 ppt. Salinitas perairan pesisir Kabupaten MTB berkisar antara 34,07 dan 34,73 ppt (Tabel 1). Salinitas yang relatif rendah dijumpai di Kecamatan Selaru, sebagai akibat adanya sungai yang bermuara di lokasi tersebut. Salinitas yang diperoleh ini relatif sama dengan yang telah ditemukan sebelumnya bahwa salinitas perairan di tiga lokasi penelitian adalah sekitar 35 ppt (DKP Kabupaten MTB, 2014). Satu hal yang sangat penting dihindari dalam aktivitas budidaya ikan dalam KJA adalah lokasi di mana potensi fluktuasi salinitas tinggi seperti muara sungai (Vairappan \& Chung, 2006). Umumnya ikan yang hidupnya menetap di laut memiliki toleransi yang tinggi terhadap salinitas. Salinitas dapat memengaruhi proses osmoregulasi dan merupakan salah satu faktor penentu terhadap pertumbuhan dan sintasannya.

Tabel 1. Nilai minimal, maksimal, dan rata-rata kualitas air yang diukur di lapangan di kawasan pesisir Kabupaten Maluku Tenggara Barat Provinsi Maluku

Table 1. Minimum, maximum, and mean value of water quality parameters measured on the coastal areas of Maluku Tenggara Barat District Maluku Province

\begin{tabular}{lccc}
\hline \multirow{2}{*}{ Parameter (Parameters) } & \multicolumn{3}{c}{ Kecamatan (Sub-districts) } \\
\cline { 2 - 4 } & Tanimbar Utara & Wuarlabobar & Selaru \\
\hline Kecepatan arus (m/dt) / Current velocity (m/sec.) & $18.4-52.8(38.46)$ & $4.3-44.7(19.46)$ & $15.1-28.2(21.03)$ \\
Arah arus (dari Utara) / Current direction (from North) & $122.5-231.6(158.00)$ & $13.5-347.1(129.48)$ & $1.6-308.5(165.02)$ \\
Kedalamam (Depth) (m) & $2.0-22.0(13.91)$ & $2.0-30.0(11.43)$ & $2.1-15.1(7.23)$ \\
Kecerahan (Transparency) (m) & $2.0-14.8(7.45)$ & $2.0-20.6(8.71)$ & $2.1-13.6(6.82)$ \\
Kecerahan (Transparency (\%) & $29-100(59.4)$ & $67-100(84.3)$ & $68-100(94.4)$ \\
Suhu (Temperature) ( $\left.{ }^{\circ} \mathrm{C}\right)$ & $26.6-29.2(27.91)$ & $27.0-28.0(27.41)$ & $26.7-28.2(27.39)$ \\
Salinitas (Salinity) (ppt) & $34.12-34.40(34.248)$ & $34.07-34.25(34.186)$ & $34.16-34.73(34.369)$ \\
Oksigen terlarut (Dissolved oxygen ) (mg/L) & $6.16-6.56(6.405)$ & $6.41-6.93(6.602)$ & $6.23-9.62(6.982)$ \\
pH & $8.15-8.29(8.206)$ & $8.22-8.92(8.351)$ \\
\hline
\end{tabular}


Konsentrasi oksigen terlarut merupakan salah satu faktor pembatas bagi ikan yang dibudidayakan. Konsentrasi oksigen terlarut dalam air dapat memengaruhi pertumbuhan, rasio konversi pakan, dan mengurangi daya dukung perairan. Ikan akan hidup dengan baik pada konsentrasi oksigen terlarut 5-8 mg/ L. Konsentrasi oksigen terlarut pada semua lokasi perairan yang diteliti di Kabupaten MTB berada pada kisaran antara 6,16-9,62 mg/L seperti terlihat dalam Tabel 1. Dengan demikian, semua lokasi budidaya ikan dalam KJA dikategorikan cukup sesuai dan sangat sesuai. Konsentrasi oksigen terlarut di lokasi yang sama telah dilaporkan sebelumnya yaitu berkisar 8,513,5 mg/L (DKP Kabupaten MTB, 2014).

Tolok ukur yang digunakan untuk menentukan kondisi perairan asam atau basa disebut $\mathrm{pH}$. Ikan diketahui mempunyai toleransi pada $\mathrm{pH}$ antara 4,011,0 dan untuk ikan-ikan karang diketahui pertumbuhannya sangat baik pada kisaran $\mathrm{pH}$ 8,0-8,2. Hal ini menunjukkan bahwa pH perairan pesisir Kabupaten MTB dapat mendukung budidaya ikan dalam KJA. pH air di Kabupaten MTB berada pada pH air laut secara umum yaitu berkisar 8,15-8,29 di Kecamatan Tanimbar Utara; 8,22-8,92 di Kecamatan Wuarlabobar; dan 8,06-8,28 di Kecamatan Selaru (Tabel 1). Nilai pH perairan yang relatif sama untuk perairan di Kecamatan Tanimbar Utara, Wuarlabobar, dan Selaru yang berurutturut berkisar 8,50-8,68; 7,52-8,70; dan 8,05-8,66 telah dilaporkan sebelumnya (DKP Kabupaten MTB, 2014).

Konsentrasi berbagai parameter kualitas air dari Kabupaten MTB yang dianalisis di laboratorium disajikan dalam Tabel 2. Nitrogen dapat berada pada berbagai bentuk, namun yang umum dijadikan parameter penting dalam perikanan budidaya termasuk kegiatan marikultur adalah nitrogen amonia total, nitrit, dan nitrat. Dari ketiga bentuk tersebut, yang paling bersifat toksin pada ikan adalah nitrogen amonia total dan nitrit, sedangkan nitrat hanya bersifat toksin pada konsentrasi yang tinggi yaitu lebih besar dari $20 \mathrm{mg} / \mathrm{L}$.

Konsentrasi nitrat yang didapatkan di Kabupaten MTB berkisar 0,1123-0,5731 mg/L. Kisaran nilai tersebut masih tergolong agak tinggi untuk kegiatan marikultur. Konsentrasi nitrat yang lebih tinggi di tempat yang sama yang berkisar 1,40 dan $1,80 \mathrm{mg} / \mathrm{L}$ (DKP Kabupaten MTB, 2014). Konsentrasi nitrat yang dapat diterima untuk biota laut dianggap kurang dari $20 \mathrm{mg} / \mathrm{L}$ (Spotte, 1979).

Nitrit merupakan indikator ada tidaknya pencemaran dan merupakan salah satu senyawa yang dibutuhkan oleh organisme akuatik. Konsentrasi nitrit pada perairan relatif kecil karena segera dioksidasi menjadi nitrat. Konsentrasi nitrit berkisar 0,0048-
0,0582 mg/L di Kecamatan Tanimbar Utara; 0,0089$0,0754 \mathrm{mg} / \mathrm{L}$ di Kecamatan Wuarlabobar; dan 0,0341$0,0678 \mathrm{mg} / \mathrm{L}$ di Kecamatan Selaru. Di tempat yang sama yaitu di Kecamatan Tanimbar Utara, Wuarlabobar, dan Selaru didapatkan berturut-turut konsentrasi nitrit 0,001-0,009 mg/L;0,001-0,004 mg/L; dan 0,001-0,009 mg/L (DKP Kabupaten MTB, 2014). Di perairan, konsentrasi nitrit jarang melebihi $1 \mathrm{mg} / \mathrm{L}$ (Sawyer \& McCarty, 1978). Konsentrasi nitrit yang lebih dari 0,05 $\mathrm{mg} / \mathrm{L}$ dapat bersifat toksin bagi organisme akuatik yang sangat sensitif (Moore, 1991).

Konsentrasi nitrogen amonia total di Kecamatan Tanimbar Utara yaitu 0,0757-0,3334 mg/L; di Kecamatan Wuarlabobar yaitu 0,1054-0,2746 mg/L; dan di Kecamatan Selaru yaitu 0,0135-0,1597 mg/L. Baku mutu air laut untuk biota laut adalah 0,3 mg/L (KLH, 2004); sehingga konsentrasi nitrogen amonia total perairan di Kabupaten MTB dapat mendukung kegiatan budidaya ikan dalam KJA. Apabila konsentrasi amonia lebih dari 0,2 $\mathrm{mg} / \mathrm{L}$; perairan bersifat toksin bagi beberapa jenis ikan (Sawyer \& M cCarty, 1978).

Fosfat merupakan salah satu senyawa nutrien yang sangat penting. Peningkatan konsentrasi fosfat dalam laut akan menyebabkan terjadinya peledakan populasi (blooming) fitoplankton yang berakibat pada kematian ikan secara massal (Hu et al., 2011; Ly et al., 2014). Konsentrasi fosfat yang didapatkan di Kecamatan Tanimbar Utara berkisar 0,0318-0,0895 mg/L; di Kecamatan Wuarlabobar berkisar 0,0366-0,1481 mg/ L; dan di Kecamatan Selaru berkisar 0,0347-0,1252 mg/ L (Tabel 2). Berdasarkan konsentrasi fosfat, kualitas air dibagi atas tiga kategori yaitu kesuburan rendah dengan konsentrasi 0-0,02 mg/L; kesuburan sedang dengan konsentrasi 0,021-0,05 mg/L; dan kesuburan tinggi dengan konsentrasi 0,051-0,10 mg/L (Liaw, 1969). Dengan demikian, berdasarkan konsentrasi fosfat perairan di kawasan pesisir Kabupaten MTB, maka perairan tersebut tergolong kesuburan sedang dan tinggi.

Padatan tersuspensi total adalah pasir, lumpur, tanah, maupun logam berat yang tersuspensi di daerah perairan. Rata-rata padatan tersuspensi total dari yang terkecil hingga terbesar di lokasi penelitian Kabupaten MTB adalah $1 \mathrm{mg} / \mathrm{L}$ hingga $161 \mathrm{mg} / \mathrm{L}$. Baku mutu padatan tersuspensi total untuk kehidupan koral dan lamun lebih rendah dari $20 \mathrm{mg} / \mathrm{L}$, sedangkan untuk mangrove lebih rendah $80 \mathrm{mg} / \mathrm{L}$ (KLH, 2004).

Bahan organik total menggambarkan konsentrasi karbon organik total suatu perairan yang terdiri atas bahan organik terlarut, tersuspensi, dan koloid. Konsentrasi bahan organik total air di lokasi kajian Kabupaten MTB relatif sama, hanya berkisar antara 55,68 dan 63,19 mg/L; seperti terlihat dalam Tabel 2. 
Tabel 2. Nilai minimal, maksimal, dan rata-rata kualitas air yang dianalisis di laboratorium dari kawasan pesisir Kabupaten Maluku Tenggara Barat Provinsi Maluku

Table 2. Minimum, maximum, and mean value of measured ex-situ water quality parameters in coastal area of Maluku Tenggara Barat District Maluku Province

\begin{tabular}{lccc}
\hline \multirow{2}{*}{ Parameter (Parameters) } & \multicolumn{3}{c}{ Kecamatan (Sub-districts) } \\
\cline { 2 - 4 } & Tanimbar Utara & Wuarlabobar & Selaru \\
\hline Nitrat (Nitrate) $(\mathrm{mg} / \mathrm{L})$ & $0.1269-0.2266(0.18404)$ & $0.1123-0.5731(0.27508)$ & $0.1301-0.3288(0.18650)$ \\
Nitrit (Nitrite) $(\mathrm{mg} / \mathrm{L})$ & $0.0048-0.0582(0.03094)$ & $0.0089-00754(0.03410)$ & $0.0341-0.0678(0.05410)$ \\
Nitrogen amonia total & $0.0757-0.3334(0.14611)$ & $0.1054-0.2746(0.18271)$ & $0.0135-0.1378(0.10251)$ \\
Total ammonia nitrogen (mg/L) & $0.0318-0.0895(0.05628)$ & $0.0366-0.1481(0.07539)$ & $0.0347-0.1252(0.10251)$ \\
$\begin{array}{l}\text { Fosfat (Phosphate) (mg/L) } \\
\text { Padatan tersuspensi total }\end{array}$ & $1-70(37.3)$ & $19-101(53.7)$ & $13-161(56.6)$ \\
$\begin{array}{l}\text { Total suspended solid (mg/L) } \\
\text { Bahan organik total } \\
\text { Total organic matter (mg/L) }\end{array}$ & $57.56-61.94(60,059)$ & $56.93-63.19(60,329)$ & $55.68-60.06(57,200)$ \\
\hline
\end{tabular}

Konsentrasi bahan organik total dalam air laut biasanya rendah dan tidak melebihi $3 \mathrm{mg} / \mathrm{L}$. Menurut Reid (1961), perairan dengan konsentrasi bahan organik total lebih besar dari $26 \mathrm{mg} / \mathrm{L}$ adalah tergolong perairan yang subur. Berdasarkan berbagai pendapat tersebut menunjukkan bahwa konsentrasi bahan organik total perairan Kabupaten MTB tergolong tinggi dan subur. Hal ini disebabkan oleh adanya hutan mangrove di kawasan pesisir yang dapat menyuplai bahan organik total perairan.

\section{Kesesuaian Perairan}

Dengan mempertimbangkan faktor kriteria dan faktor pembatas telah ditetapkan kesesuaian lahan untuk budidaya ikan dalam KJA (Tabel 3 dan Gambar 1) di Kabupaten MTB. Kedalaman perairan merupakan faktor kriteria yang membatasi kesesuaian perairan untuk budidaya ikan dalam KJA di Kabupaten MTB. Untuk evaluasi kesesuaian perairan untuk budidaya ikan dalam KJA, faktor pembatas merupakan parameter penting yang harus dipertimbangkan. Parameter penting yang dapat dikategorikan sebagai faktor pembatas kegiatan marikultur, di antaranya padang lamun, pelabuhan kapal, kawasan industri, dan kawasan pariwisata (Pérez et al., 2003).

Dari $67.287,84$ ha kawasan pesisir yang diteliti di Kecamatan Tanimbar Utara, Wuarlabobar, dan Selaru sebagian kecil yaitu $1.564,43$ ha $(2,32 \%$ yang tergolong sangat sesuai (S-1) dan sebagian besar yaitu $52.931,71$ ha $(79,20 \%$ tergolong tidak sesuai (N) untuk budidaya ikan dalam KJA (Gambar 1). Namun demikian disarankan agar budidaya ikan dalam KJA hanya dilakukan pada kawasan pesisir yang tergolong S1 dan $\mathrm{S} 2$, sedangkan yang tergolong S3 dan N untuk kawasan konservasi.

\section{Daya Dukung Perairan}

Penggunaan kawasan perairan Kabupaten MTB sebagai lokasi kegiatan budidaya ikan dalam KJA sudah mulai berkembang, walaupun lebih banyak dalam kegiatan penampungan ikan hasil tangkapan. Namun demikian, dalam pengembangannya ke depan perlu ditunjang dengan evaluasi daya dukung perairan berbasis kawasan berkelanjutan. Oleh karena itu, telah dibuat estimasi daya dukung perairan yang disesuaikan dengan kondisi perairan di Kabupaten MTB. Penilaian daya dukung perairan didasarkan pada pemikiran bahwa perairan pesisir memiliki kapasitas maksimal untuk mendukung suatu pertumbuhan organisme akuatik. Pengembangan budidaya ikan dalam KJA dilakukan dengan konsep daya dukung sesuai persyaratan tumbuhnya dengan tetap memperhatikan dimensi-dimensi yang berpengaruh baik internal dan eksternal.

Pengembangan usaha budidaya ikan dalam KJA juga diharapkan tetap memperhatikan prinsip kelestarian dan keberkelanjutan. Untuk itu, potensi yang ada sebaiknya tidak dimanfaatkan seluruhnya, tetapi disediakan area yang berfungsi sebagai penyangga yang dapat menekan efek penurunan kualitas lingkungan. Area penyangga ini dapat dibuat dengan mengatur jumlah unit KJA. Radiarta et al. (2004) menyarankan untuk penempatan jumlah unit KJA yang ideal dalam zona budidaya tidak lebih dari $10 \%$ dari luas ideal. Dengan demikian, luas lahan yang dapat dimanfaatkan untuk budidaya ikan dalam KJA di kawasan pesisir Kecamatan Tanimbar Utara, Wuarlabobar, dan Selaru berturut-turut 363, 292, dan 570 ha. Untuk luasan 1 ha dapat dimanfaatkan secara efektif untuk 15 unit KJA dengan ukuran $8 \mathrm{~m} \times 8 \mathrm{~m}$ setiap unit KJA. Oleh 
Tabel 3. Kelas kesesuaian perairan untuk budidaya ikan dalam keramba jaring apung di Kabupaten Maluku Tenggara Barat Provinsi Maluku

Table 3. Waters suitability classes for fish culture in floating net cage in Maluku Tenggara Barat District Maluku Province

\begin{tabular}{|c|c|c|c|c|c|}
\hline \multirow{2}{*}{$\begin{array}{l}\text { Kelas kesesuaian perairan } \\
\text { Waters suitability classes }\end{array}$} & \multicolumn{3}{|c|}{ Kecamatan (Sub-districts) (ha) } & \multirow{2}{*}{$\begin{array}{l}\text { Total } \\
\text { (ha) }\end{array}$} & \multirow{2}{*}{$\begin{array}{c}\text { Persentase } \\
\text { Percentage }(\%\end{array}$} \\
\hline & Tanimbar Utara & Wuarlabobar & Selaru & & \\
\hline Sangat sesuai (Very suitable) (S1) & 108.15 & - & $1,456.28$ & $1,564.43$ & 2.32 \\
\hline Cukup sesuai (Moderately suitable) (S2) & $3,525.00$ & $2,917.85$ & $4,244.93$ & $10,687.78$ & 15.88 \\
\hline Kurang sesuai (Marginally suitable) (S3) & 708.23 & 654.60 & 741.09 & $2,103.92$ & 3.14 \\
\hline Tidak sesuai (Not suitable) (N) & $7,842.25$ & $21,175.94$ & $23,913.52$ & $52,931.71$ & 78.66 \\
\hline Total & $12,183.63$ & $24,748.39$ & $30,355.82$ & $67,287.84$ & 100.00 \\
\hline
\end{tabular}

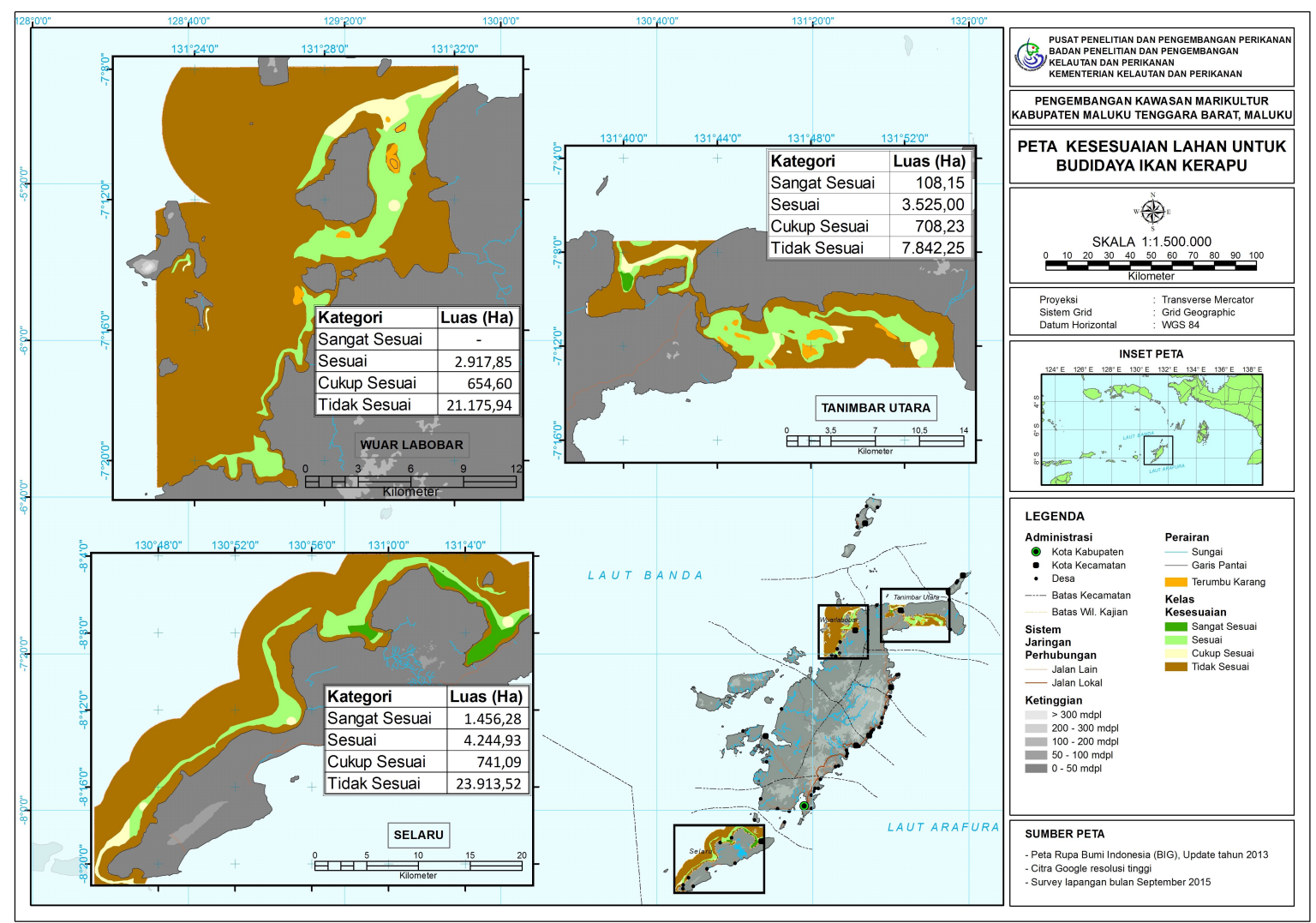

Gambar 1. Peta kesesuaian perairan untuk budidaya ikan dalam keramba jaring apung di kawasan pesisir Kabupaten Maluku Tenggara Barat Provinsi Maluku.

Figure 1. Waters suitability map for fish culture in the floating net cage in coastal area of Maluku Tenggara Barat District Maluku Province.

karena itu, jumlah unit KJA ukuran $8 \mathrm{~m} \times 8 \mathrm{~m}$ yang dapat diaplikasikan di kawasan perairan Kecamatan Tanimbar Utara, Wuarlabo bar, dan Selaru berturut-turut $5.445,4.380$, dan 8.550 unit (Tabel 4). Komoditas yang dapat dibudidayakan dalam KJA adalah ikan kerapu, ikan kakap, ikan beronang, ikan kuwe, dan lobster.

\section{KESIMPULAN DAN SARAN}

Secara umum karakteristik perairan Kecamatan Tanimbar Utara, Wuarlabobar, dan Selaru, Kabupaten Maluku Tenggara Barat dapat mendukung kegiatan budidaya ikan dalam keramba jaring, namun kedalaman perairan yang relatif dangkal dan sangat dalam yang 
Tabel 4. Daya dukung perairan dan jumlah keramba jaring apung untuk pengembangan budidaya ikan dalam keramba jaring apung di perairan pesisir Kabupaten Maluku Tenggara Barat Provinsi Maluku

Table 4. Waters carrying capacity and number of floating net cage for developing of fish culture in floating net cage in coastal area of Maluku Tenggara Barat Regency Maluku Province

\begin{tabular}{|c|c|c|}
\hline $\begin{array}{l}\text { Kecamatan } \\
\text { Subdistricts }\end{array}$ & $\begin{array}{l}\text { Daya dukung lahan } \\
\text { Waters carrying capacity (ha) }\end{array}$ & $\begin{array}{c}\text { Jumlah unit keramba jaring apung* } \\
\text { Number of floating net cage* }\end{array}$ \\
\hline Tanimbar Utara & 363 & 5,445 \\
\hline W uarlabobar & 292 & 4,380 \\
\hline Selaru & 570 & 8,550 \\
\hline Total & 1,225 & 18,375 \\
\hline
\end{tabular}

menjadi faktor pembatas dalam kesesuaian perairan untuk kegiatan budidaya ikan dalam keramba jaring apung. Dari 67.287,84 hakawasan pesisir yang diteliti di Kabupaten Maluku Tenggara Barat dijumpai kawasan pesisir yang tergolong sangat sesuai seluas $1.564,43$; cukup sesuai seluas $10.687,78 \mathrm{ha}$; kurang sesuai sesuai 2.103,92 ha; dan tidak sesuai seluas 52.931,71 ha untuk budidaya ikan dalam keramba jaring apung. Di ketiga kawasan pesisir Kecamatan Tanimbar Utara, Wuarlabobar, dan Selaru dapat dilakukan budidaya ikan dalam keramba jaring apung dengan pengembangan kawasan maksimal masing-masing seluas 363, 292, dan 570 ha yang dapat digunakan untuk masing-masing $5.445,4.380$, dan 8.550 unit keramba jaring apung ukuran $8 \mathrm{~m} \times 8 \mathrm{~m}$. Disarankan agar pengembangan kawasan untuk budidaya ikan dalam keramba jaring apung di Kabupaten Maluku Tenggara Barat dimulai pada kawasan pesisir yang tergolong sangat sesuai kemudian menyusul pada kawasan pesisir yang tergolong cukup sesuai, sedangkan yang tergolong kurang sesuai dan tidak sesuai untuk kawasan konservasi.

\section{UCAPAN TERIMA KASIH}

Diucapkan terima kasih kepada Bapak Hakim Madeng dan Muhammad Arnol atas bantuannya dalam pengambilan contoh air dan sedimen di lapangan. Terima kasih juga disampaikan kepada Kepala dan staf Dinas Kelautan dan Perikanan Kabupaten Maluku Tenggara Barat atas bantuannya selama pelaksanaan penelitian ini. Juga diucapkan terima kasih kepada Ibu Siti Rohani dan Kurniah atas analisis kualitas air di laboratorium. Penelitian ini dibiayai dari Daftar Isian Pelaksanaan Anggaran yang ada di Pusat Penelitian dan Pengembangan Perikanan Budidaya Tahun Anggaran 2015.

\section{DAFTAR ACUAN}

Ahmad, T., Imanto, P.T., Muchari, Basyarie, A., Sunyoto, P., Slamet, B., Mayunar, Purba, R., Diana, S., Redjeki, S., Pranowo, S.A., \& Murtiningsih, S. (1991). Operasional pembesaran ikan kerapu dalam keramba jaring apung. Departemen Pertanian. Jakarta, $59 \mathrm{hlm}$.

American Public Health Association [APHA]. (2012). Standard methods for the examination of water and wastewater. American Public Health Association - American Water Works Association - Water Environment Federation, Washington, D.C., 1496 pp.

Ayllón, D., Almodóvar, A., Nicola, G.G., Parra, I., \& Elvira, B. (2012). Modelling carrying capacity dynamics for the conservation and management of territorial salmonids. Fisheries Research, 134-136, 95-103.

Bano, S., Rawat, J.S., Shashikant, Ranga, V., Sharm, A., \& Sharma, R. (2016). Site suitability analysis for fish farming using Heuristic Approach Method - A case study in Silangtoli Village of Bageshwar District (Uttarakhand). International Journal of Science, Engineering and Technology Research, 5(2), 548-551.

Beveridge, M.C.M. (1996). Cage aqua-culture. Second edition. England: Fishing News Books Ltd. Farnham, Surrey, $352 \mathrm{pp}$.

van Diepen, C.A., van Keulen, H., Wolf, J., \& Berkhout, J.A.A. (1991). Land evaluation: from intuition to quantification. In Stewart, B.A. (Ed.). Advances in Soil Science. New York: Springer, p. 139-204.

Dinas Kelautan dan Perikanan Kabupaten Maluku Tenggara Barat [DKP Kabupaten MTB]. (2014). Penyusunan Data Potensi Kelautan dan Perikanan, 
Kabupaten Maluku Tenggara Barat. Dinas Kelautan dan Perikanan Kabupaten Maluku Tenggara Barat, Saumlaki, $112 \mathrm{hlm}$.

Effendi, I., Suprayudi, M.A., Surawidjaja, E.H., Supriyono, E., Zairin, Jr.M., \& Sukenda. (2016). Production performance of white shrimp (Litopenaeus vannamei) under sea floating net cages with biofloc and periphyton juvenile. AACL Bioflux, 9(4), 823-832.

Food and Agriculture Organization [FAO]. (1985). Guidelines: Land evaluation for irrigated agriculture. In FAO Soil Bulletin 55. Soil Resources Management and Conservation Service and Water Development Division, Food and Agriculture Organization. Rome, $231 \mathrm{pp}$.

Grigorakis, K. \& Rigos, G. (2011). Aquaculture effects on environmental and public welfare - the case of Mediterranean mariculture. Chemosphere, 85, 899-919.

Gorlach-Lira, K., Pacheco, C., Carvalho, L.C.T., Melo Júnior, H.N., \& Crispim, M.C. (2013). The influence of fish culture in floating net cages on microbial indicators of water quality. Brazilian Journal of Biology, 73(3), 457-463.

Hasnawi, Makmur, Paena, M., \& Mustafa, A. (2013). Analisis kesesuaian lahan budidaya rumput laut (Kappaphycus alvarezii) di Kabupaten Parigi Moutong Provinsi Sulawesi Tengah. Jurnal Riset Akuakultur, 8(3), 493-505.

Hu, H., Zhang, J., \& Chen, W. (2011). Competition of bloom-forming marine phytoplankton at low nutrient concentrations. Journal of Environmental Sciences, 23(4), 656-663.

Kementerian Kelautan dan Perikanan [KKP]. (2015). Kelautan dan Perikanan dalam Angka 2015. Kementerian Kelautan dan Perikanan, Jakarta, $308 \mathrm{hlm}$.

Kementerian Kelautan dan Perikanan [KKP] News. (2017). Revitalisasi keramba jaring apung (KJA) budidaya laut. KKP News. http://news.kkp.go.id/ index.php/tingkatkan-produksi-budidaya-denganrevitalisasi-kja/. Diakses 20 Maret 2017.

Kementerian Lingkungan Hidup [KLH]. (2004). Keputusan Menteri Negara Kependudukan dan Lingkungan Hidup No. 51 Tahun 2004, Tanggal 8 April 2004 tentang Baku Mutu Air Laut untuk Biota Laut. Kementerian Lingkungan Hidup. Jakarta, $11 \mathrm{hlm}$.

Liaw, W.K. (1969). Chemical and biological studies of fishponds and reservoirs in Taiwan. Reprinted from Chinese-American Joint Commission on Rural Reconstruction, Fish Series, 7, 1-43.
Ly, J., Philippart, C.J.M., \& Kromkamp, J.C. (2014). Phosphorus limitation during a phytoplankton spring bloom in the western Dutch Wadden Sea. Quaternary Research, 88, 109-120.

Malczewski, J. (1999). GIS and mutlicriteria decision analysis. New York: John Wiley \& Sons, 392 pp.

Mayunar, Purba, R., \& Imanto, P.T. (1995). Pemilihan lokasi untuk usaha budidaya ikan laut. Dalam Sudradjat, A., Ismail, W., Priono, B., Murniyati, \& Pratiwi, E. (Eds.). Prosiding Temu Usaha Pemasyarakatan Teknologi Keramba Jaring Apung bagi Budidaya Laut. Jakarta, 12-13 April 1995. Badan Penelitian dan Pengembangan Pertanian. Departemen Pertanian, hlm. 179-189.

Moore, J.W. (1991). Inorganic contaminants of surface water: Research and Monitoring Priorities. New York: Springer-Verlag, 326 pp.

Morain, S. (1999). GIS solution in natural resource management: Balancing the technical political equation. USA: On Word Press, $361 \mathrm{pp}$.

Mustafa, A., Radiarta, I N., \& Rachmansyah. (2011). Profil dan kesesuaian lahan akuakultur mendukung minapolitan. Diedit Sudradjat, A. Pusat Penelitian dan Pengembangan Perikanan Budidaya. Jakarta, $91 \mathrm{hlm}$.

Mustafa, A., Tarunamulia, Hasnawi, \& Radiarta, I N. (2017). Karakteristik, kesesuaian dan daya dukung perairan untuk budidaya rumput laut di Kabupaten Kepulauan Sangihe, Sulawesi Utara. Jurnal Riset Akuakultur, 12(2), 187-196.

Pérez, O.M., Ross, L.G., Telfer, T.C., \& del Campo Barquin, L.M. (2003). Water quality requirements for marine fish cage site selection in Tenerife (Canary Islands): Predictive modelling and analysis using GIS. Aquaculture, 224, 51-68.

Philipose, K.K., Sharma, S.R.K., Loka, J., Divu, D., Sadhu, N., \& Dube, P. (2013). Culture of Asian seabass (Lates calcarifer, Bloch) in open sea floating net cages of Karwar, south India. Indian Journal Fisheries, 60(1), 67-70.

Price, C., Black, K.D., Hargrave, B.T., \& Morris Jr.J.A. (2015). Marine cage culture and the environment: Effects on water quality and primary production. Aquaculture Environment Interactions, 6, 151-174.

Purnawan, S., Zaki, M., Asnawi, T.M., \& Setiawan, I. (2015). Studi penentuan lokasi budidaya kerapu menggunakan keramba jaring apung di perairan Timur Simeulue. Depik, 4(1), 40-48.

Radiarta, I N., Erlania, \& Sugama, K. (2014). Budidaya rumput laut, Kappaphycus alvarezii secara terintegrasi dengan ikan kerapu di Teluk Gerupuk Kabupaten Lombok Tengah, Nusa Tenggara Barat. Jurnal Riset Akuakultur, 9(1), 111-124. 
Radiarta, I N., Hasnawi, \& Mustafa, A. (2013). Kondisi kualitas perairan di Kabupaten Morowali Provinsi Sulawesi Tengah: Pendekatan spasial dan statistik multivariate. Jurnal Riset Akuakultur, 8(2), 299-309.

Radiarta, I N., Saputra, A., \& Priono, B. (2004). Pemetaan kelayakan lahan untuk pengembangan usaha budidaya laut di Teluk Saleh, Nusa Tenggara Barat. Jurnal Penelitian Perikanan Indonesia, 9(1): 19-30.

Ramelan, H.S. (1998). Pengembangan budidaya ikan laut di Indonesia. Dalam Sudradjat, A., Heruwati, E.S., Sugama K., Poernomo, A., Azwar, Z.I., \& Giri, I N.A. (Eds.). Prosiding Teknologi Perikanan Pantai. Badan Penelitian dan Pengembangan Pertanian, Departemen Pertanian. Jakarta, hlm. 59-79.

Reid, G.K. (1961). Ecology of inland waters and estuaries. New York: Van Nostrand Reinhold Co., $375 \mathrm{pp}$.

Richard, J.U. \& Ogba, C. (2016). Site selection analysis for suitable aquaculture fish pond in Andoni L.G.A. Rivers State, Nigeria. International Journal of Research - Granthaalayah, 4(3), 219-232.

Rodriguez-Gallego, L., Achkar, M., \& Conde, D. (2012). Land suitability assessment in the catchment area of four Southwestern Atlantic Coastal Lagoons: Multicriteria and optimization modeling. Environmental Management, 50, 140-152.

Ross, L.G., Telfer, T.C., Falconer, L., Soto, D., AguilarManjarrez, J., Asmah, R., ..., \& Zhu, C. (2013). Carrying capacities and site selection within the ecosystem approach to aquaculture. In Ross, L.G., Telfer, T.C., Falconer, L., Soto, D., \& AguilarManjarrez, J. (Eds.). Site selection and carrying capacities for inland and coastal aquaculture. FAO/ Institute of Aquaculture, University of Stirling, Expert Workshop, 6-8 December 2010, Stirling, the United Kingdom of Great Britain and Northern Ireland. FAO Fisheries and Aquaculture Proceedings No. 21. Rome: FAO, p. 19-46.
Saaty, T.L. (1977). A scaling method for priorities in hierarchical structures. Journal of Mathematical Psychology, 15, 234-281.

Sawyer, C.N. \& McCarty, P.L. (1978). Chemistry for environmental engineering. Third edition. New York: McGraw-Hill Book Company, 532 pp.

Silva-Cruz, Y., Castañeda-Chávez, M. del R., LangoReynoso, F., \& Landeros-Sánchez, C. (2011). Environmental impact of fish farming in floating cages in Isla Arena, Campeche. Tropical and Subtropical Agroecosystems, 13, 291-298.

Singh, S.P., Sharma, J.G., Ahmad, T., \& Chakrabarti, R. (2013). Effect of water temperature on the physiological responses of Asian catfish Clarias batrachus (Linnaeus 1758). Asian Fisheries Science, 26, 26-38.

Spotte, S. (1979). Fish and invertebrate culture: Water management in closed system. New York: John Wiley and Sons, 179 pp.

Stigebrandt, A. (2011). Carrying capacity: General principles of model construction. Aquaculture Research, 42(1), 41-50.

Sutrisyani \& Rohani, S. (2009). Panduan praktis analisis kualitas air payau. Cetakan kedua. Diedit Rachmansyah, Atmomarsono, M., \& Mustafa, A. Pusat Riset Perikanan Budidaya. Jakarta, $55 \mathrm{hlm}$.

Tarunamulia, Hasnawi, Suhaemi, R.A., Mustafa, A., \& Paena, M. (2015). Perspektif pengembangan perikanan budidaya berdasarkan karakteristik pantai di Teluk Gerupuk dan Teluk Bumbang Kabupaten Lombok Tengah Provinsi Nusa Tenggara Barat. Jurnal Riset Akuakultur, 10(1), 117-126.

Vairappan, C.S. \& Chung, C.S. (2006). Seaweed farming in Malaysia: Challenges. In Moi, S.P., Critchley, A.T., \& Ang, P.O. (Eds.). Advances in seaweed cultivation and utilization in Asia. Proceedings of a Workshop Seventh Asian Fisheries Forum, Malaysia. Maritime Research Centre, University of Malaya, Kuala Lumpur, p. 161-169. 